\title{
Aberrant Chloride Transport Contributes to Anoxic/Ischemic White Matter Injury
}

\author{
Sameh A. Malek, Elaine Coderre, and Peter K. Stys \\ Ottawa Health Research Institute, Ottawa Hospital, University of Ottawa, Canada K1Y 4K9
}

Rundown of ionic gradients is a central feature of white matter anoxic injury; however, little is known about the contribution of anions such as $\mathrm{Cl}^{-}$. We used the in vitro rat optic nerve to study the role of aberrant $\mathrm{Cl}^{-}$transport in anoxia/ischemia. After 30 min of anoxia $\left(\mathrm{NaN}_{3}, 2 \mathrm{mM}\right)$, axonal membrane potential $\left(V_{\mathrm{m}}\right)$ decreased to $42 \pm 11 \%$ of control and to $73 \pm 11 \%$ in the presence of tetrodotoxin (TTX) $(1 \mu \mathrm{M})$. TTX $+4,4^{\prime}$-diisothiocyanatostilbene-2,2' disulfonic acid disodium salt $(500 \mu \mathrm{M})$, a broad spectrum anion transport blocker, abolished anoxic depolarization ( $95 \pm 8 \%$ ). Inhibition of the K-Cl cotransporter (KCC) (furosemide $100 \mu \mathrm{M}$ ) together with TTX was also more effective than TTX alone $(84 \pm 14 \%)$. The compound action potential (CAP) area recovered to $26 \pm 6 \%$ of control after $1 \mathrm{hr}$ anoxia. KCC blockade (10 $\mu \mathrm{m}$ furosemide) improved outcome ( $40 \pm 4 \%)$, and TTX (100 nM) was even more effective $(74 \pm 12 \%)$. In contrast, the $\mathrm{Cl}^{-}$channel blocker niflumic acid $(50 \mu \mathrm{M})$ worsened injury $(6 \pm 1 \%)$. Coapplication of TTX $(100 \mathrm{nM})+$ furosemide $(10 \mu \mathrm{M})$ was more effective than either agent alone $(91 \pm 9 \%)$. Furosemide was also very effective at normalizing the shape of the CAPs. The KCC3a isoform was localized to astrocytes. KCC3 and weaker KCC3a was detected in myelin of larger axons. KCC2 was seen in oligodendrocytes and within axon cylinders. $\mathrm{Cl}^{-}$gradients contribute to resting optic nerve membrane potential, and transporter and channel-mediated $\mathrm{Cl}^{-}$ fluxes during anoxia contribute to injury, possibly because of cellular volume changes and disruption of axo-glial integrity, leading to propagation failure and distortion of fiber conduction velocities.

Key words: anoxia; ischemia; axon; chloride; $\mathrm{K}-\mathrm{Cl}$ cotransporter; KCC

\section{Introduction}

Anoxia/ischemia induces cellular ionic deregulation caused by failure of regulatory mechanisms such as ATPases and coupled ion exchangers. As shown previously in CNS white matter, with the fall in energy substrates, axonal $\mathrm{Na}^{+}$overload occurs that in turn initiates $\mathrm{Ca}^{2+}$ accumulation in large part through reverse operation of the $\mathrm{Na}^{+} / \mathrm{Ca}^{2+}$ exchanger (Stys et al., 1992). In anoxic CNS axons, $\mathrm{Na}^{+}$overload is essentially balanced by an equivalent efflux of $\mathrm{K}^{+}$from the axoplasm (LoPachin and Stys, 1995; Stys and LoPachin, 1998), thus maintaining an electroneutral exchange of ions. One might therefore expect that restraining $\mathrm{Na}^{+}$influx into axoplasm during anoxia (e.g., by applying tetrodotoxin (TTX) or replacing bath $\mathrm{Na}^{+}$with an impermeant cation) would secondarily reduce $\mathrm{K}^{+}$loss. Unexpectedly, axoplasmic $\mathrm{K}^{+}$depletion is not restrained in anoxic optic nerve axons even when $\mathrm{Na}^{+}$overload is blocked by TTX (Stys and LoPachin, 1998). Instead, $\mathrm{K}^{+}$loss is balanced by efflux of $\mathrm{Cl}^{-}$and likely other organic anions (Stys and LoPachin, 1998). Anion transporters including $\mathrm{Na}-\mathrm{K}-2 \mathrm{Cl}$ (NKCC) cotransporter, $\mathrm{Na}^{+}{ }_{-}$ coupled $\mathrm{Cl}^{-} / \mathrm{HCO}_{3}{ }^{-}$exchange, and the $\mathrm{KCl}$-cotransporter (KCC) play an important role in intracellular $\mathrm{Cl}^{-}$regulation in central neurons (Kaila, 1994). Given its cotransport of $\mathrm{K}^{+}$and $\mathrm{Cl}^{-}$, KCC would be a plausible candidate for mediating the observed parallel efflux of these ions during anoxia under condi-

\footnotetext{
Received Dec. 2, 2002; revised Jan. 23, 2003; accepted Feb. 27, 2003.

This work was supported in part by National Institute of Neurological Disorders and Stroke Grant R01 NS4008701. S.A.M. is supported by a studentship from the Ontario Neurotrauma Foundation. P.K.S. is supported by a Career Investigator Award from the Heart and Stroke Foundation of Ontario.

Correspondence should be addressed to Dr. Peter K. Stys, Ottawa Health Research Institute, Division of Neuroscience, 725 Parkdale Avenue, 0ttawa, Ontario, Canada K1Y 4K9. E-mail: pstys@ohri.ca.

Copyright $\odot 2003$ Society for Neuroscience $\quad$ 0270-6474/03/233826-11\$15.00/0
}

tions when $\mathrm{Na}^{+}$overload is restrained (as may occur during attempts at neuroprotection with $\mathrm{Na}^{+}$channel blockers or glutamate receptor antagonists). The emergence of $\mathrm{K}^{+}-\mathrm{Cl}^{-}$coefflux under such conditions may have important implications for cellular integrity, because osmotically obligated water loss may have deleterious effects on cellular volume and therefore mechanical integrity, and in addition, this loss of water may in turn paradoxically concentrate remaining ions ( such as $\mathrm{Na}^{+}$) to toxic levels (see Discussion).

There are currently four known isoforms of the KCC (Gillen et al., 1996; Payne et al., 1996; Mount et al., 1999), which are part of the larger family of cation-coupled cotransporter proteins that also includes the $\mathrm{Na}-\mathrm{K}-2 \mathrm{Cl}$ cotransporter. Identified in 1996 by Payne and colleagues, the neuronal isoform (KCC2) appears to mainly extrude $\mathrm{Cl}^{-}$out of the cell under physiological conditions (Payne et al., 1996). KCC3 has been shown to have a robust expression in the brain (Mount et al., 1999) with a cellular localization to white matter tracts (Pearson et al., 2000, 2001). On the basis of the fact that during anoxia and $\mathrm{Na}^{+}$-channel inhibition there is persistent decay in membrane potential (Leppanen and Stys, 1997), probably as a result of $\mathrm{K}^{+}$efflux that proceeds in conjunction with $\mathrm{Cl}^{-}$exit (Stys et al., 1997), we hypothesized that blockade of $\mathrm{Cl}^{-}$loss during anoxia/ $\mathrm{Na}^{+}$-channel inhibition will impede $\mathrm{K}^{+}$efflux and protect white matter against anoxia better than $\mathrm{Na}^{+}$-channel blockers alone. We confirmed that combined inhibition of $\mathrm{Na}^{+}$influx and $\mathrm{K}^{+}+\mathrm{Cl}^{-}$efflux via the KCC reduced anoxic depolarization and improved compound action potential (CAP) recovery to a greater extent than $\mathrm{Na}^{+}$ channel inhibitors alone. Moreover, quantitative evaluation of the CAP wave-shape revealed that combined treatment also greatly improved not only CAP area but also the shape, suggest- 

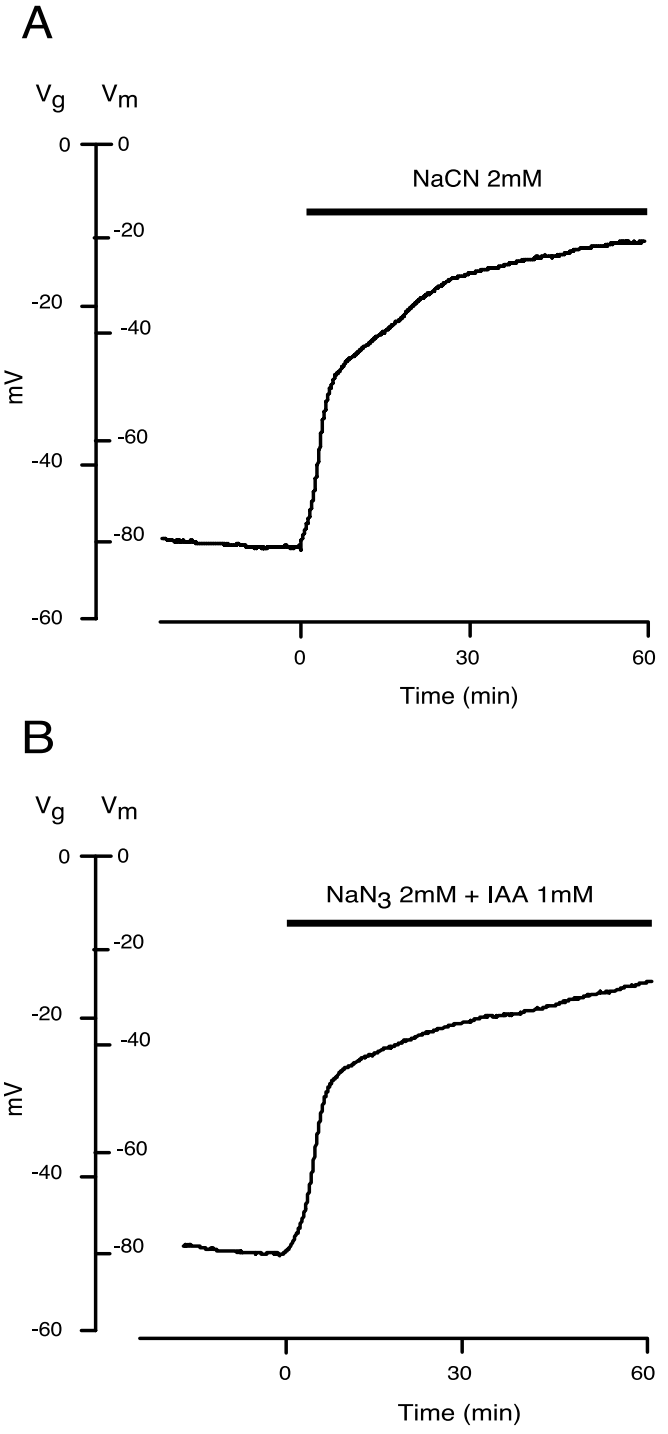

Figure 1. Effect of chemical anoxia and ischemia on the membrane potential of rat optic nerve. $V_{\mathrm{g}}$ represents recorded gap potential and $V_{\mathrm{m}}$ represents membrane potential. Time 0 in this and all subsequent figures denotes application of insult. $A, \mathrm{NaCN}(2 \mathrm{~mm})$ caused a rapid loss of membrane potential decaying to $\sim 42 \pm 11$ and $32 \pm 10 \%$ of control at 30 and 60 min, respectively, of chemical anoxia. $B$, Chemical ischemia, $2 \mathrm{~mm} \mathrm{NaN}_{3}+1 \mathrm{~mm} I A A$, caused a decay of $41 \pm 5$ and $31 \pm 6 \%$ after 30 and 60 min of perfusion.

ing a preservation of the underlying tissue architecture (e.g., maintenance of axo-glial relationships or myelin integrity that would preserve conduction velocities of constituent fibers). We therefore suggest that, at least for white matter, combined $\mathrm{Na}^{+}$ channel inhibition and reduction of secondary $\mathrm{K}^{+}$and $\mathrm{Cl}^{-}$efflux represents an improved neuroprotective strategy.

\section{Materials and Methods}

Electrophysiology. Compound resting membrane potential was recorded from optic nerves in vitro dissected free from adult Long-Evans rats. One nerve was recorded immediately using a grease gap chamber at $37^{\circ} \mathrm{C}$ as described previously (Leppanen and Stys, 1997), whereas the second was stored in oxygenated artificial CSF (ACSF) containing (in mM): 126 $\mathrm{NaCl}, 3 \mathrm{KCl}, 26 \mathrm{NaHCO}_{3}, 2 \mathrm{MgSO}_{4}, 1.25 \mathrm{NaH}_{2} \mathrm{PO}_{4}, 2 \mathrm{CaCl}_{2}$, and 10 glucose, $\mathrm{pH}$ 7.45) at room temperature for later study. No consistent differences were noted between nerves recorded immediately and those held for later study. Raw baseline gap potentials $\left(V_{\mathrm{g}}\right)$ varied from nerve to nerve (typical range -45 to $-50 \mathrm{mV}$ ) because of differences in the short circuit factor (Stämpfli, 1954). Therefore for display purposes all poten-
Table 1. Summary of different pharmacological manipulations and their effects on membrane potential of rat optic nerve expressed as means \pm SD

\begin{tabular}{lllr}
\hline Treatment & $30 \min \left(\% V_{\mathrm{m}}\right)$ & $60 \mathrm{~min}\left(\% V_{\mathrm{m}}\right)$ & $n$ \\
\hline Chemical ischemia (OGD) & $41 \pm 5$ & $31 \pm 6$ & 10 \\
Chemical anoxia & $42 \pm 11$ & $32 \pm 10$ & 14 \\
$\quad$ DIDS 500 $\mu \mathrm{M}$ & $43 \pm 8$ & $40 \pm 9$ & 2 \\
Furosemide 10 $\mu \mathrm{M}$ & $57 \pm 8$ & $46 \pm 10$ & 2 \\
TTX 1 $\mu \mathrm{M}$ & $73 \pm 11$ & $63 \pm 18$ & 12 \\
TTX 1 $\mu \mathrm{M}+$ DIDS 500 $\mu \mathrm{M}$ & $95 \pm 8$ & $89 \pm 6$ & 13 \\
TTX 1 $1 \mu \mathrm{M}+$ furosemide 100 $\mu \mathrm{M}$ & $84 \pm 14$ & $79 \pm 16$ & 20 \\
ONa & $77 \pm 9$ & $73 \pm 10$ & 3 \\
ONa/DIDS & $92 \pm 3$ & $84 \pm 5$ & 5 \\
\hline
\end{tabular}

Values were obtained from ratios comparing 30 and $60 \min V_{\mathrm{g}}$ values with those at time 0 , which denotes time of onset of chemical anoxia or ischemia. Drugs were preapplied for $60 \mathrm{~min}$.

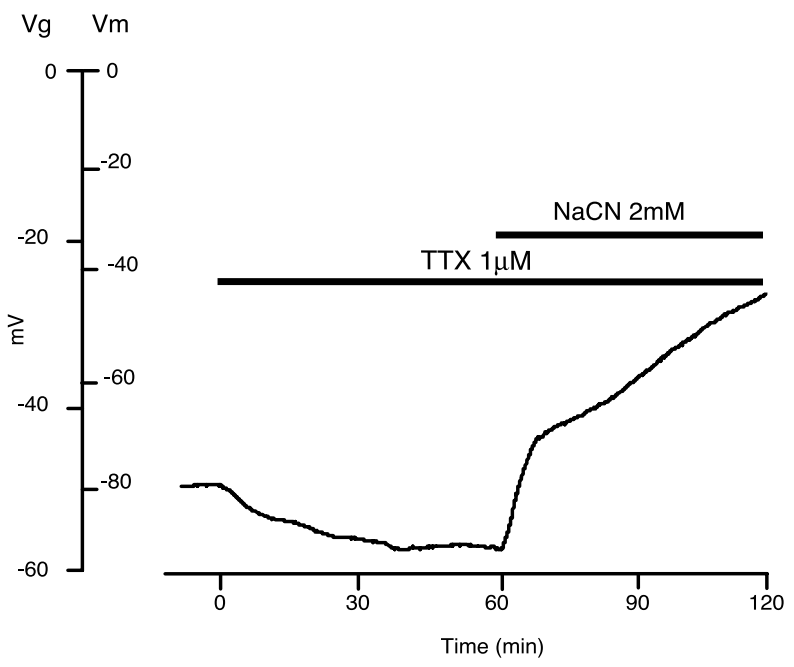

Figure 2. Effect of $\mathrm{Na}^{+}$-channel inhibition on the membrane potential of rat optic nerve. TTX (1 $\mu \mathrm{M})$ preapplied for $1 \mathrm{hr}$ before chemical anoxia caused a brief hyperpolarization of $V_{m}$, thus indicating the presence of a $\mathrm{Na}^{+}$conductance at rest. During chemical anoxia, $1 \mu \mathrm{m} \mathrm{TTX}$ blunted the rapid phase of the characteristic depolarization $\left(73 \pm 11 \%\right.$ of control $V_{m}$ remaining after 30 min in TTX + anoxia vs $42 \pm 11 \%$ with anoxia alone, $p<0.005 ; 63 \pm 18 \%$ after 60 min, $p<0.001 ; n=12$ ), suggesting that $\mathrm{Na}^{+}$influx through TTX-sensitive channels constitutes one of the primary events in producing the anoxic depolarization.

tials were normalized (denoted $V_{\mathrm{m}}$ ) to the true resting potential of CNS myelinated axons of $-80 \mathrm{mV}$ (Stys et al., 1997). Quantitative comparisons over time were performed using ratios of recorded potentials; therefore, this normalization had no effect on such calculations. For technical reasons, we were unable to obtain reproducible responses in the grease gap chamber using $\mathrm{N}_{2} / \mathrm{CO}_{2}$ as a means of inducing anoxia, even with the use of oxygen scavengers (data not shown). This was likely because of the configuration of the chamber, which prevented adequate isolation allowing some ambient $\mathrm{O}_{2}$ to access the nerves, resulting in excessively variable recordings. Instead we elected to induce anoxia chemically (Leppanen and Stys, 1997) with either $\mathrm{CN}^{-}$or $\mathrm{N}_{3}{ }^{-}$, which gave similar results.

Propagated compound action potentials were recorded using suction electrodes as described previously (Stys et al., 1991). Briefly, nerves were placed in an interface perfusion chamber, perfused with ACSF $(2 \mathrm{ml} /$ min, $37^{\circ} \mathrm{C}$ ), and gassed with either $95 \% \mathrm{O}_{2}$ or $95 \% \mathrm{~N}_{2}$, balance $\mathrm{CO}_{2}$. Supramaximal constant voltage stimuli were delivered and responses were recorded using a pair of glass suction electrodes. Anoxia was achieved by switching to $\mathrm{N}_{2} / \mathrm{CO}_{2}$, and ischemia was simulated by exposure to anoxia with equimolar replacement of glucose by sucrose [oxygen-glucose deprivation (OGD)].

Pharmacology. TTX (Alomone Labs) was prepared as a stock solution in distilled water. 4,4'-Diisothiocyanatostilbene-2,2' disulfonic acid disodium salt (DIDS), furosemide, bumetanide, and niflumic acid were purchased from Sigma (St. Louis, MO). DIDS was added directly to the desired volume of ACSF solution to make up the required concentration. 
A

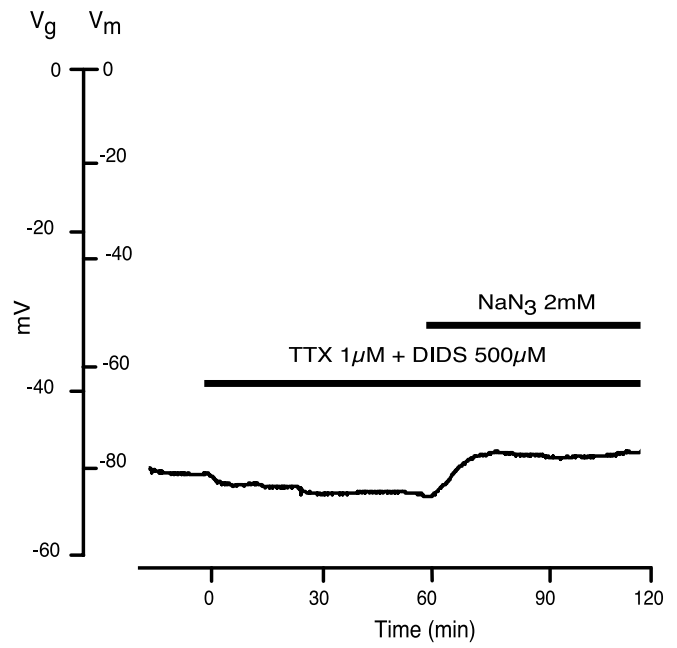

B

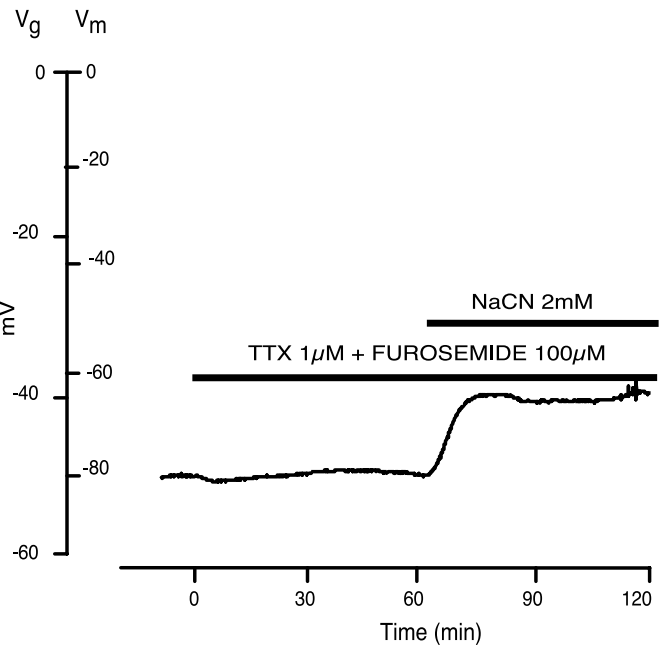

Figure 3. Effect of anion transport and $\mathrm{Na}^{+}$-channel co-blockade on the membrane potential of rat optic nerve during chemical anoxia. $A$, DIDS $(500 \mu \mathrm{M})$, a broad-spectrum anion transport blocker, applied during normoxic conditions, had no effect on $1 \mu \mathrm{m}$ TTX hyperpolarization. During chemical anoxia, the combined treatment allowed for maximum maintenance of $V_{\mathrm{m}}$ ( $95 \pm 8$ vs $73 \pm 10 \%$ in TTX alone at $30 \mathrm{~min}, p<0.001 ; 89 \pm 6$ vs $63 \pm 18 \%$ at $60 \mathrm{~min}, p<$ $0.001 ; n=13$ ), suggesting an anion component for the depolarization. $B$, Furosemide (100 $\mu \mathrm{M})$, a relatively specific blocker for $\mathrm{KCC}$, produced a blunting of the residual depolarization seen with TTX $+\mathrm{CN}^{-}$(84 $\pm 14 \% V_{\mathrm{m}}$ remaining after $30 \mathrm{~min}$ in TTX + furosemide vs $73 \pm$ $10 \%$ in TTX alone at $30 \mathrm{~min}, p<0.05 ; 79 \pm 16$ vs $63 \pm 18 \%, p<0.05 ; n=20$ ). This suggests that the DIDS effect is mediated primarily, but not exclusively, via KCC.

Furosemide was first dissolved in DMSO. Both bumetanide and niflumic acid were dissolved in ethanol. $\mathrm{NaCN}$ was acquired from $\mathrm{BDH}$ (Toronto, Ontario, Canada). $\mathrm{NaN}_{3}$ was purchased from Fisher Scientific. All other salts were purchased from Sigma.

All errors are reported as SDs, and statistical significance was assessed using a Student's $t$ test. All experimental protocols were approved by the institutional animal care committee.

Immunohistochemistry. Deeply anesthetized Long-Evans rats (200$300 \mathrm{gm}$ ) were perfused transcardially with $0.9 \%$ saline followed by $2 \%$ paraformaldehyde containing $20 \mathrm{~mm}$ L-lysine, $2.5 \mathrm{~mm}$ sodium periodate, and $2.5 \%$ potassium dichromate. The optic nerves were postfixed for $2 \mathrm{hr}$ and immersed in $0.1 \mathrm{~m}$ PBS for $24 \mathrm{hr}$. The protocol was as follows: wash three times for $10 \mathrm{~min}$ each in Tris buffer containing $1.5 \% \mathrm{NaCl}$ and $0.3 \%$ Triton X-100 (TBS-T) and incubate for $30 \mathrm{~min}$ at $4^{\circ} \mathrm{C}$ in methanol; wash three times for 10 min each in TBS-T; block with 10\% normal goat serum in TBS-T for $1 \mathrm{hr}$ at room temperature; and incubate overnight

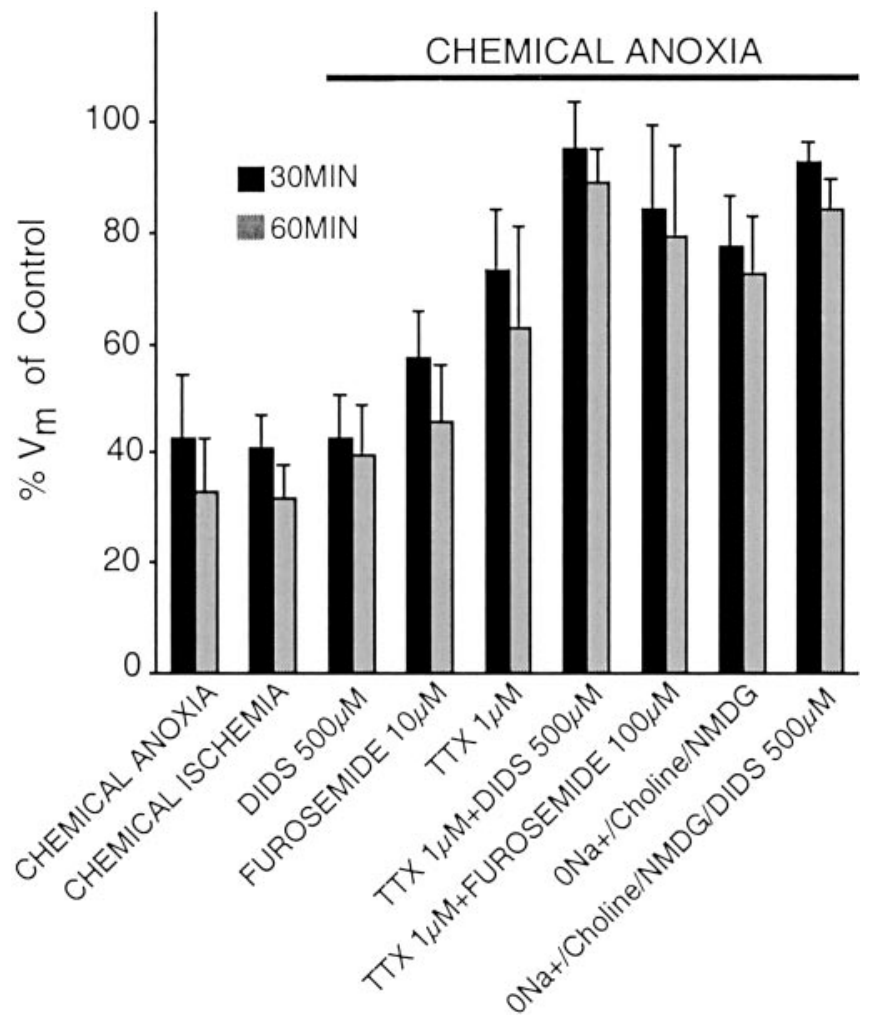

Figure 4. Summary of different pharmacological manipulations and their effects on $V_{m}$ of rat optic nerve. Both chemical anoxia and ischemia caused comparable decay profiles. Anion transport blockers, $500 \mu \mathrm{m}$ DIDS and $10 \mu \mathrm{m}$ furosemide, when used alone during chemical anoxia were ineffective in maintaining $V_{\mathrm{m}}$ at pre-anoxic levels. $\mathrm{Na}^{+}$-channel blockade, $1 \mu \mathrm{m}$ $\pi \mathrm{TX}$, was more effective in preserving $V_{\mathrm{m}}$ to a large extent during chemical anoxia. Nevertheless, there existed a residual portion of the depolarization, which was $\mathrm{Na}{ }^{+}$independent as seen from inhibition of either $\mathrm{Na}^{+}$channels or $\mathrm{Na}^{+}$replacement. Co-blockade of $\mathrm{Na}^{+}$channel (1 $\mu \mathrm{M}$ TTX) and anion transport (500 $\mu \mathrm{M} \mathrm{DIDS)} \mathrm{or} \mathrm{Na}^{+}$replacement (NMDG) in combination with $500 \mu \mathrm{m}$ DIDS produced a robust maintenance of $V_{\mathrm{m}}$. Furosemide (100 $\left.\mu \mathrm{m}\right)$, KCC blocker, coapplied with $1 \mu \mathrm{M}$ TTX, improved $V_{\mathrm{m}}$ maintenance as compared with TTX alone. However, the levels were not as comparable as those of DIDS, presumably because there are other pathways involved in mediating residual $V_{\mathrm{m}}$ depolarization during TTX/chemical anoxia perfusion.

with primary antibody diluted in TBS-T containing $2 \%$ normal goat serum. All KCC primary antibodies (Chemicon, Temecula, CA) were diluted at a concentration of $5 \mu \mathrm{g} / \mathrm{ml}$ and $16 \mu \mathrm{g} / \mathrm{ml}$ for neurofilament 160 (NF160; Sigma, Oakville, Ontario, Canada). The next day, the optic nerves were washed three times for $10 \mathrm{~min}$ each in TBS-T. Goat antirabbit Cy2 (1:200) and goat anti-mouse Texas Red (1:100; Jackson ImmunoResearch, West Grove, PA) were used for secondaries. Sections were imaged on a Bio-Rad 1024 or Nikon C1 confocal with $60 \times$ oil immersion objective.

\section{Results}

$V_{\mathrm{g}}$ recordings in ACSF typically stabilized 90 min after insertion into the grease gap chamber. Raw control resting potentials ranged from -45 to $-50 \mathrm{mV}$. No consistent differences were noted between the first and second nerves studied sequentially. To compare responses over time and between different treatments, ratios of $V_{\mathrm{g}}$ values were calculated at different time points (typically 30 and $60 \mathrm{~min}$ ) with respect to potentials at time 0 (defined as a stable potential baseline before any experimental treatment).

\section{Effects of $\mathrm{Cl}^{-}$transport inhibition on membrane potential $\left(V_{\mathrm{m}}\right)$ during anoxia}

We elected to induce anoxia chemically, using $2 \mathrm{~mm}$ either $\mathrm{NaCN}$ or $\mathrm{NaN}_{3}$, inhibitors of complex IV of the respiratory chain 

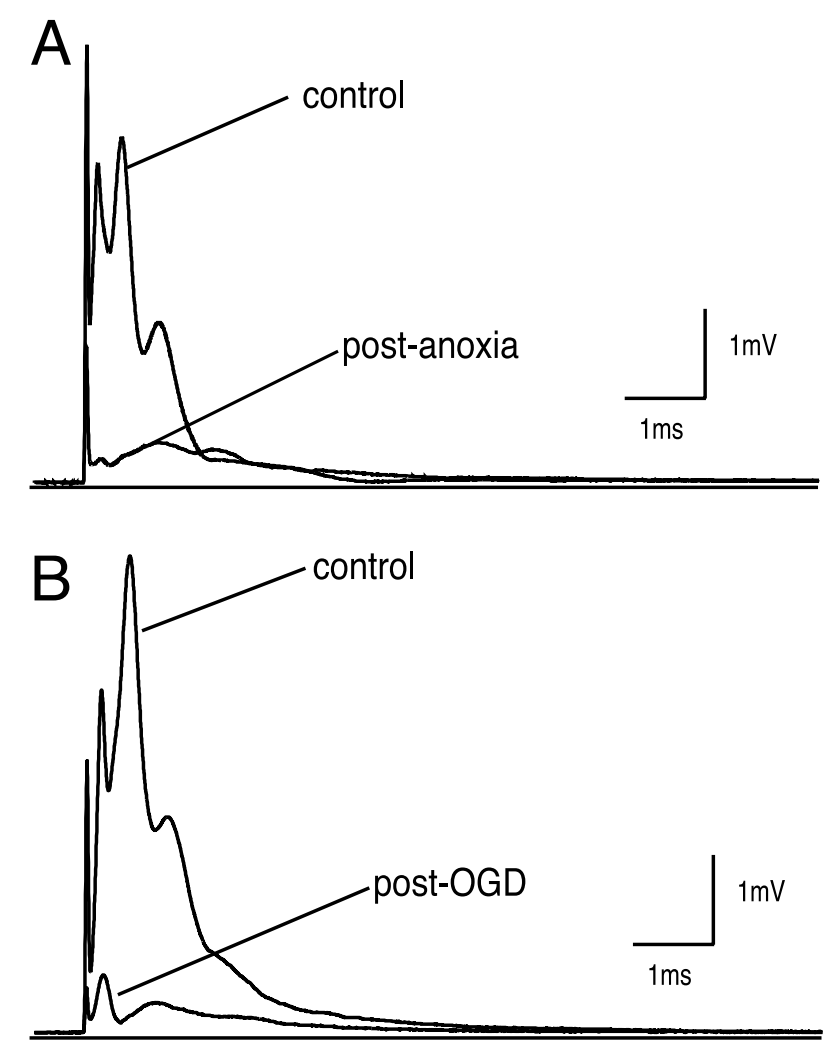

Figure 5. Effects of anoxia versus oxygen/glucose deprivation (OGD) on the compound action potential of the rat optic nerve. $A$, Recovery of the CAP area after 60 min anoxic insult in normal ACSF was $26 \pm 6 \%$ of control at $3 \mathrm{hr}$ after reoxygenation. $B$, With the stronger insult of $60 \mathrm{~min} 0 \mathrm{GD}$, the recovery was only $8 \pm 4 \%$ of control, also at $3 \mathrm{hr}$ after reoxygenation.

(Kauppinen and Nicholls, 1986; Tadic, 1992). Figure $1 A$ shows a typical response to chemical anoxia induced by $\mathrm{CN}^{-}$. Resting membrane potential depolarized within minutes, decaying to $44 \pm 14$ and to $34 \pm 13 \%$ of control after 30 and $60 \mathrm{~min} . \mathrm{N}_{3}{ }^{-}$ produced very similar results $(40 \pm 6$ and $30 \pm 5 \%$ of control potential remaining after 30 and $60 \mathrm{~min}$ ). Results from both treatments were therefore combined in subsequent analyses (Table 1). Chemical ischemia was induced by combining $\mathrm{NaN}_{3}(2$ $\mathrm{mM}$ ) and iodoacetic acid- $\mathrm{Na}^{+}$salt (IAA) $(1 \mathrm{mM})$, an irreversible blocker of the glycolytic enzyme glyceraldehyde-3-phosphate dehydrogenase (Sabri and Ochs, 1971). $V_{\mathrm{m}}$ decayed to values comparable with those observed with chemical anoxia alone (41 \pm 5 and $31 \pm 6 \%$ at 30 and $60 \mathrm{~min}$, respectively) $(n=10)$ (Fig. $1 B$ ).

Previous reports have demonstrated the effectiveness of $\mathrm{Na}^{+}$ channel inhibition as a neuroprotective strategy in anoxic white matter (Stys et al.,1992; Fern et al., 1993; Leppanen and Stys, 1997). The effects of TTX $(1 \mu \mathrm{M})$ on optic nerve resting membrane potential during anoxia or ischemia are illustrated in Figure 2 and quantitatively in Figure 4. Application of TTX under normoxic conditions caused a hyperpolarization as observed previously (Stys et al., 1993; Leppanen and Stys, 1997). Depolarization was less pronounced in anoxic nerves exposed to TTX (73 \pm $11 \%$ of control $V_{\mathrm{m}}$ remaining after $30 \mathrm{~min}$ in TTX + anoxia vs $42 \pm 11 \%$ with anoxia alone, $p<0.01 ; 63 \pm 18 \%$ after $60 \mathrm{~min}$, $p<0.001 ; n=12)$. Replacement of $\mathrm{Na}^{+}$with an impermeant cation during chemical anoxia resulted in a blunted depolarization to $77 \pm 9 \%$ of control membrane potential at $30 \mathrm{~min}(p<$ 0.01 vs chemical anoxia) and to $73 \pm 10 \%$ after $60 \mathrm{~min}(p<0.01$; $n=3$ ) (see Fig. 4). Because neither of the above manipulations completely prevented anoxic depolarization, other non- $\mathrm{Na}^{+}$-
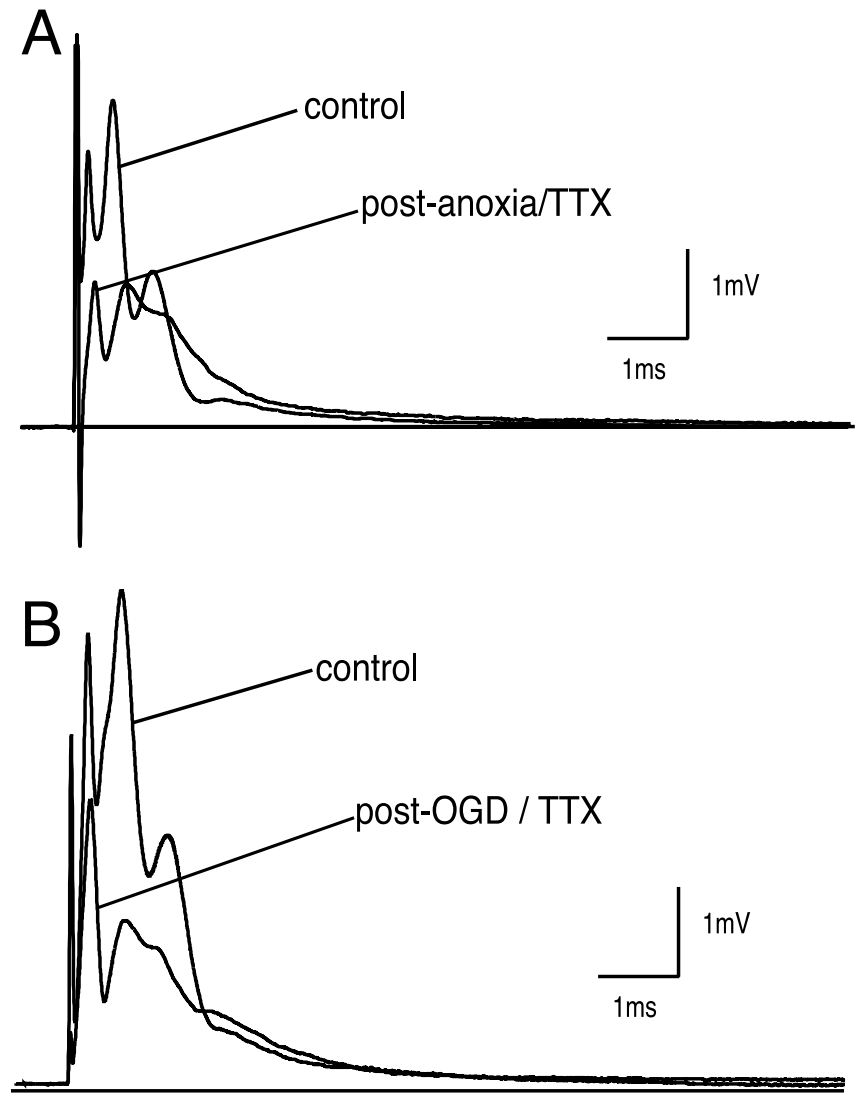

Figure 6. Effect of $\mathrm{Na}^{+}$-channel blockers on CAP recovery during either anoxia or OGD. $A$, TTX (100 nM) significantly improved recovery. A $1 \mathrm{hr}$ pre-anoxic application abolished CAP. TTX was then continued for $30 \mathrm{~min}$ after anoxic insult of $60 \mathrm{~min}$. CAP area recovered to $75 \pm 12 \%$ $(p<0.001 ; n=12)$ of control at the $3 \mathrm{hr}$ post-anoxia mark. B, A 30 min pre-OGD application was continued for another $30 \mathrm{~min}$ after a $60 \mathrm{~min} 0 \mathrm{GD}$ insult. CAP area recovered significantly to $56 \pm 4 \%$ in comparison with $0 G D$ alone $(8 \pm 3 \% ; p<0.001 ; n=3)$.

dependent pathways promoting loss of resting membrane potential in anoxic axons may exist.

The role of anion transporters on resting membrane potential during anoxia was studied using DIDS, a broad-spectrum anion transport blocker that acts on the $\mathrm{K}^{+}-\mathrm{Cl}^{-}$cotransporter (Russell, 2000), volume-sensitive $\mathrm{Cl}^{-}$channels (Estevez et al., 1999), $\mathrm{Cl}^{-}-\mathrm{HCO}_{3}{ }^{-}$exchange (Clark et al., 1998; Sakai and Tosaka, 1999), and hyperpolarization-activated $\mathrm{Cl}^{-}$channels (Clark et al., 1998). In contrast, DIDS has no reported effect on $\mathrm{Na}^{+}-\mathrm{K}^{+}$$2 \mathrm{Cl}^{-}$or $\mathrm{Na}^{+}-\mathrm{Cl}^{-}$cotransporters (Russell, 2000). DIDS (500 $\mu \mathrm{M}$ ) alone did not alter the anoxic depolarization $(43 \pm 8 \%, p=$ 0.99 vs chemical anoxia at $30 \mathrm{~min} ; 40 \pm 9 \%$ at $60 \mathrm{~min}, p=0.45$; $n=2$ ) (see Fig. 4).

Previous results indicate that $\mathrm{Na}^{+}$channel inhibition promotes efflux of $\mathrm{Cl}^{-}$in parallel with $\mathrm{K}^{+}$from anoxic optic axons (Stys and LoPachin, 1998); thus concomitant blockade of $\mathrm{Na}^{+}$influx and $\mathrm{Cl}^{-}$-efflux pathways would be expected to spare $\mathrm{K}^{+}$efflux and further reduce anoxic depolarization. Application of TTX $(1 \mu \mathrm{M})$ together with $500 \mu \mathrm{M}$ DIDS (Figs. 3A, 4) reduced the amount of depolarization to a greater degree than TTX alone $(95 \pm 8$ vs $73 \pm 10 \%$ in TTX alone at $30 \mathrm{~min}, p<0.001 ; 89 \pm 6$ vs $63 \pm 18 \%$ at $60 \mathrm{~min}, p<0.001 ; n=13$ ) (Fig. $3 A$ ). DMSO $(0.2 \% \mathrm{v} / \mathrm{v}$ used for DIDS stock solutions) had no effect on the anoxia-induced membrane potential changes (data not shown). Zero $\mathrm{Na}^{+} /$choline/NMDG reduced anoxic depolarization to a similar extent as did TTX, and addition of DIDS (500 $\mu \mathrm{M})$ to the 

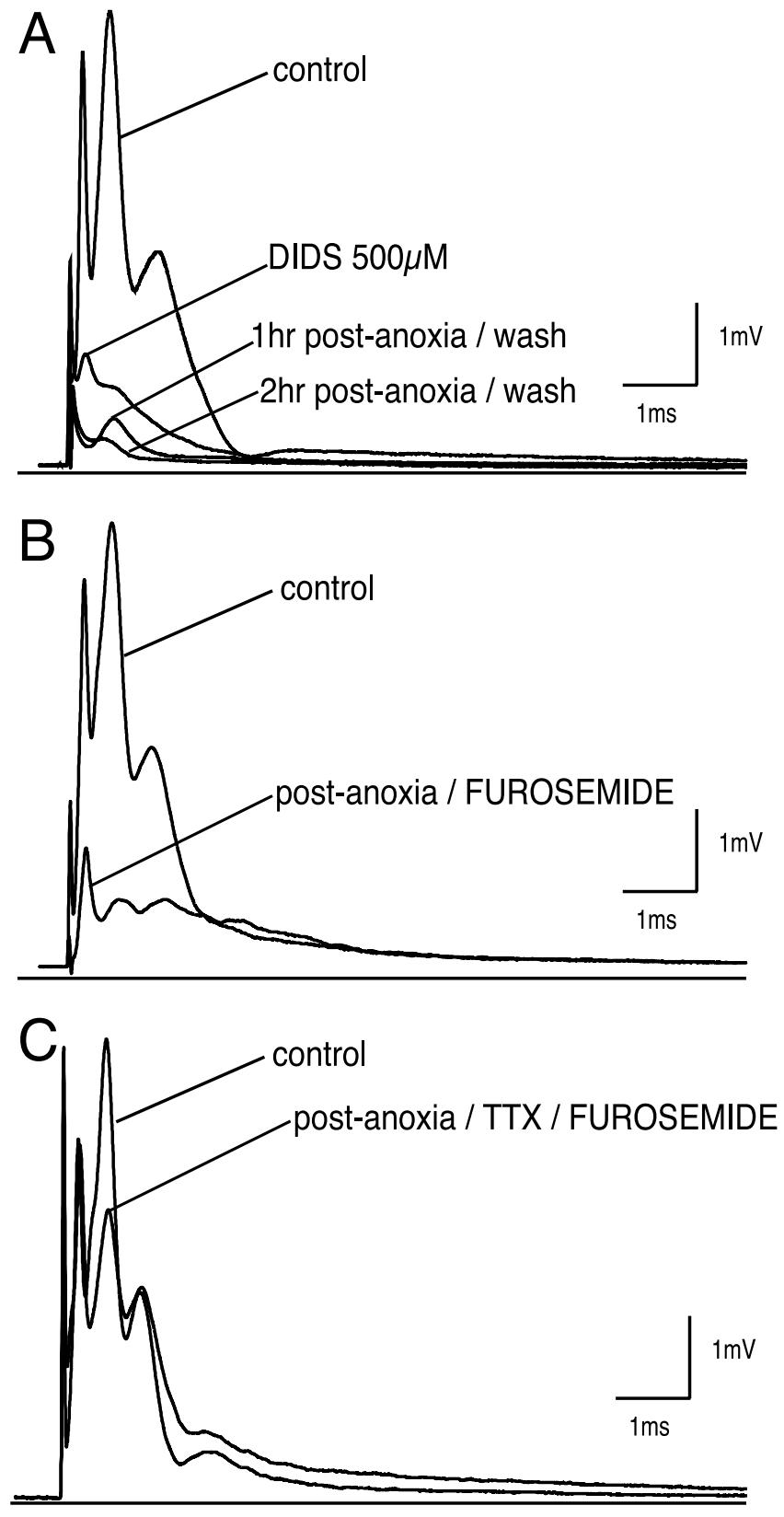

Figure 7. Effect of anion transport blockade on compound action potential during in vitro anoxia. A, DIDS (500 $\mu \mathrm{M})$ applied for $1 \mathrm{hr}$ during normoxic conditions and continued up to 30 min after anoxia caused a severe depression of CAP after a $1 \mathrm{hr}$ normoxic drug application. Furthermore, CAP recovered to $6 \pm 5 \%$ compared with $24 \pm 13 \%$ at $2 \mathrm{hr}$ after anoxia ( $p<$ 0.001 vs anoxia; $n=8$ ). Such an effect is presumably caused by the interaction of DIDS with $\mathrm{Na}^{+}$channel (Liu et al., 1998). B, Furosemide (10 $\mu \mathrm{M}$ ) applied for $1 \mathrm{hr}$ and also continued up to 30 min after anoxia had no effect on normoxic CAP but improved CAP area recovery to $40 \pm 4 \%$ $(p<0.01$ vs anoxia; $n=8)$. C, Effect of combined $\mathrm{Na}^{+}{ }^{+}$-channel and K-Cl cotransport blockade on the compound action potential of the rat optic nerve during anoxia. TTX (100 nM) and furosemide $(10 \mu \mathrm{M})$ was more protective than either agent alone (TTX + furosemide $91 \pm 8 \%$ vs $74 \pm 12 \%$ TTX alone; $p<0.001 ; n=11)$.

zero- $\mathrm{Na}^{+}$perfusate was even more effective (Fig. 4) ( $V_{\mathrm{m}}$ maintained at $92 \pm 3 \%$ of control after $30 \mathrm{~min}$ in zero- $\mathrm{Na}^{+}$DIDS vs $77 \pm 9 \%$ in zero- $\mathrm{Na}^{+}$alone).

Of the many anion transporters inhibited by DIDS, one potential route that could mediate both $\mathrm{Cl}^{-}$and $\mathrm{K}^{+}$flux is the KCC. More selective inhibition of this transporter with furosemide $(100 \mu \mathrm{M})$, a relatively specific blocker of KCC at this concentration (for review, see Cabantchik and Greger, 1992; Payne,
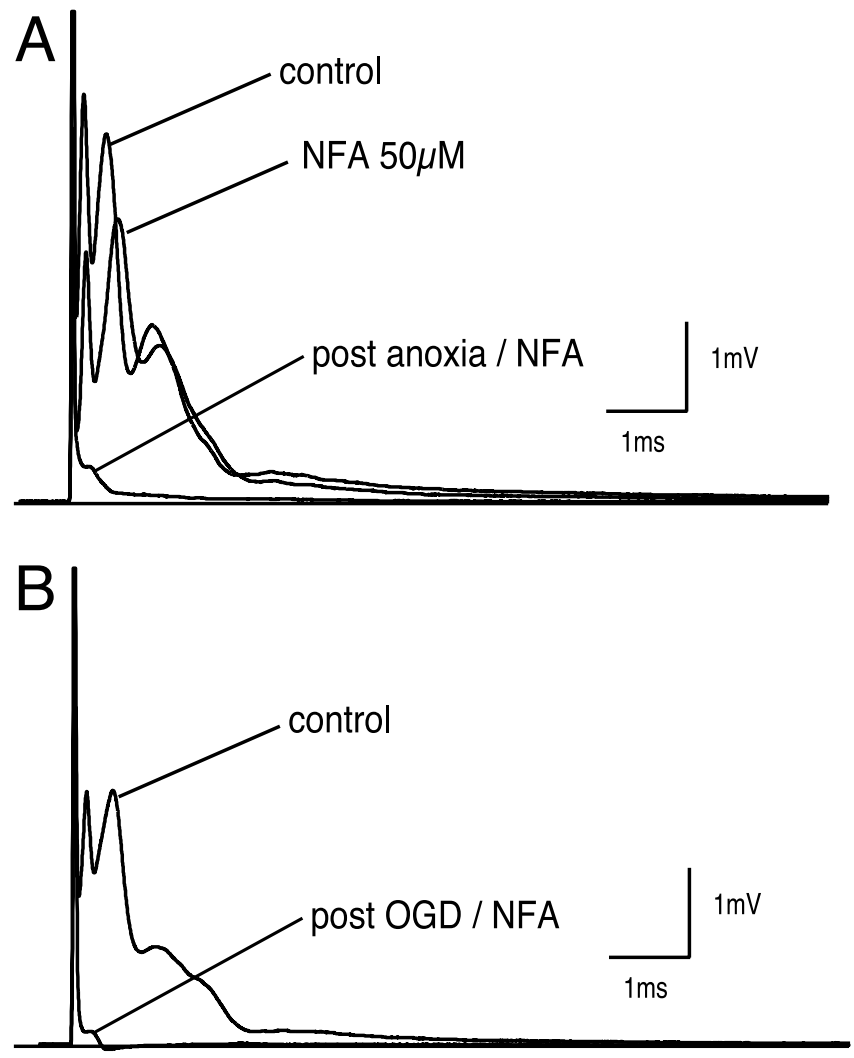

Figure 8. Evaluation of $\mathrm{Ca}^{2+}$-activated $\mathrm{Cl}^{-}$channel during in vitro anoxia and ischemia. $A$, Niflumic acid (NFA; $50 \mu \mathrm{M}$ ) caused a minor but statistically insignificant depression of normoxic CAP when perfused for $1 \mathrm{hr}$. NFA $(50 \mu \mathrm{m})$ worsened CAP recovery compared with anoxia alone $(6.0 \pm 0.7$ vs $26 \pm 6 \%$ at $3 \mathrm{hr}$ after anoxia; $p<0.01 ; n=6)$. B, Similarly, with $0 \mathrm{GD}$, the recovery worsened to $3 \pm 1$ vs $8 \pm 3 \%$ at $3 \mathrm{hr}(p<0.05 ; n=3)$. These results suggest that niflumic acid-sensitive $\mathrm{Cl}^{-}$channels (e.g., $\mathrm{Ca}^{2+}$-activated or volume-regulated $\mathrm{Cl}^{-}$channels) may play a protective role during anoxic/ischemic conditions.

1997) reduced anoxic depolarization more than TTX alone (Figs. $3 B, 4)\left(84 \pm 14 \% V_{\mathrm{m}}\right.$ remaining after $30 \mathrm{~min}$ in TTX + furosemide vs $73 \pm 10 \%$ in TTX alone at $30 \mathrm{~min}, p<0.01 ; 79 \pm 16$ vs $63 \pm 18 \%$ at $60 \mathrm{~min}, p<0.05 ; n=20$ ). However, the fact that DIDS reduced anoxic depolarization more than furosemide suggests that additional $\mathrm{Cl}^{-}$transport pathways were operating in parallel (TTX + DIDS vs TTX + furosemide; $p<0.05$ at both 30 and $60 \mathrm{~min})$.

\section{Effects of $\mathrm{Cl}^{-}$transport inhibition on the propagated compound action potential}

Figure $5 A$ shows a typical control CAP recorded from optic nerve under normoxic conditions and $3 \mathrm{hr}$ in normoxia after $1 \mathrm{hr}$ of anoxic insult. The area of the CAP recovered to $24 \pm 12 \%(n=$ 46) of control after $1 \mathrm{hr}$ anoxia/reoxygenation, in agreement with previous reports (Stys et al., 1992). In vitro ischemia (1 hr of OGD) (Figs. $5 B, 9$ ) allowed mean CAP area recovery of only $8 \pm$ $3 \%$ of control after $3 \mathrm{hr}$ of reperfusion $(n=9)$.

Previous reports have shown that axoplasmic $\mathrm{Na}^{+}$overload, a primary event in the injury cascade, occurs mainly through TTXsensitive channels during anoxia/ischemia and trauma (for review, see Stys, 1998). Nerves subjected to $1 \mathrm{hr}$ of anoxia in the presence of TTX $100 \mathrm{nM}$ (Fig. 6A) recovered to $74 \pm 12 \%$ of control CAP area versus $26 \pm 6 \%$ without TTX after $3 \mathrm{hr}$ of reoxygenation and wash in TTX-free $\operatorname{ACSF}(p<0.001 ; n=12)$ (Figs. 6A,9). This prolonged wash period was necessary to maximize removal of the blocker, which was still incomplete (control 


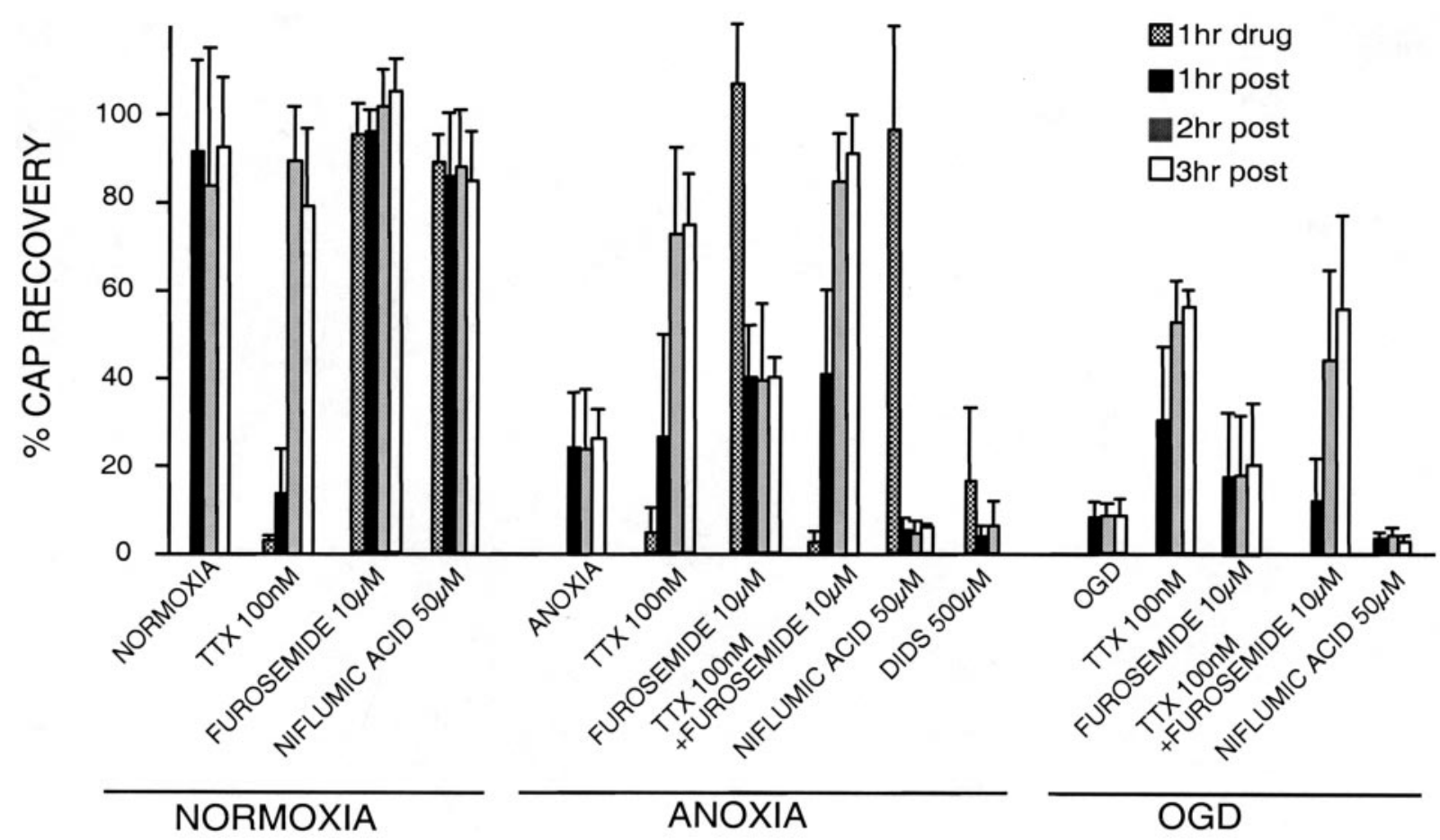

Figure 9. Quantitative effects of different pharmacological manipulations on CAP. Normoxia, TTX (100 nм) caused a reversible depression of CAP. Neither furosemide (10 $\mu \mathrm{m})$ nor NFA (50 $\mu \mathrm{M})$ had any effect on CAP during normoxia. Anoxia, A marked improvement of CAP was seen with TTX (100 nM) perfusion with a maximum recovery of $74 \pm 12 \%$ at $3 \mathrm{hr}$ after anoxia. KCC blockade allowed for $40 \pm 4 \%$ recovery versus $26 \pm 6 \%$ with anoxia $(p<0.01)$. This reflects the aberrant activity of the transporter during anoxia. DIDS $(500 \mu \mathrm{m})$, on the other hand, because of its unspecific effect, caused depression of the CAP during normoxic application (16 $\pm 17 \%)$. After $2 \mathrm{hr}$ of reoxygenation, the CAP recovered partially to only $6 \pm 5 \%$, which is far below the value observed with anoxia alone at this time point $(23 \pm 13 \% ; p<0.001 ; n=8)$. The combination of $\mathrm{Na}^{+}$channel and $\mathrm{KCC}$ blockade was the most effective manipulation in producing maximal recovery of CAP after anoxia $(91 \pm 9$ vs $74 \pm 12 \%$ TTXalone; $p<0.001 ; n=11)$. 0 n the other hand, $\mathrm{Ca}^{2+}$-activated $\mathrm{Cl}^{-}$-channel blockade caused a deterioration of the CAP with a recovery of $5 \pm 2,5 \pm 2$, and $6.0 \pm$ $0.9 \%$ at 1,2 , and $3 \mathrm{hr}$ after anoxia ( $p<0.01 ; n=6$; at $3 \mathrm{hr}$ reoxygenation vs anoxia alone). $0 \mathrm{GD}$, Under this paradigm, only $8 \pm 3 \%$ of control CAP area was rescued when measured at $3 \mathrm{hr}$ after $0 G D$ normoxic perfusion $(n=9)$. As with anoxia, a robust recovery was seen with $\mathrm{Na}^{+}$-channel blockade with TTX ( $\left.100 \mathrm{~nm}\right)(56 \pm 4 \mathrm{vs} 8 \pm 3 \% 3 \mathrm{hr}$ reoxygenation; $p<0.01 ; n=3)$. Similarly, KCC inhibition by furosemide $(10 \mu \mathrm{M})$ recovered $20 \pm 14 \%$ of control CAP area measured at $3 \mathrm{hr}$ after $\operatorname{OGD}(p<0.05 ; n=9)$.

CAPs recovered to only $80 \%$ after a similar exposure to TTX/ wash period without anoxia). As expected with the more severe ischemic insult ( $1 \mathrm{hr}$ of OGD) (Figs. 5B, 9), mean CAP area recovered to only $8 \pm 3 \%$ of control. Nevertheless TTX (100 nM) partially rescued the nerves from ischemia as well (Figs. 6B, 9), allowing $56 \pm 4 \%$ CAP area recovery after $3 \mathrm{hr}$ of reperfusion/ wash $(p<0.01 ; n=3)$.

Anion transport blockade using $500 \mu \mathrm{M}$ DIDS caused an irreversible depression of the CAP to $16 \pm 17 \%$ after $1 \mathrm{hr}$ normoxic perfusion (Figs. 7A, 9). At $2 \mathrm{hr}$ after anoxia, the CAP recovered to only $6 \pm 5 \%(p<0.001$ vs anoxia; $n=8)$. Hence we could not assess the effect of DIDS on CAP (in contrast to $V_{\mathrm{m}}$ ). The effect of KCC inhibition on CAP recovery was assessed during normoxic, anoxic, and ischemic conditions. Furosemide $(10 \mu \mathrm{M})$, a relatively specific KCC inhibitor at these concentrations (AlvarezLeefmans, 1990; Jarolimek et al., 1999), had no effect on the control CAP (see Fig. 9). However, this blocker partially prevented anoxic (mean CAP area recovery $40 \pm 4$ vs $26 \pm 6 \%$ without furosemide; $p<0.01 ; n=8$ ) (Figs. $7 B, 9$ ) and ischemic $(20 \pm 14$ vs $8 \pm 3 \% ; p<0.05 ; n=9)$ injury as measured by CAP area.

The axoplasmic anoxia-induced $\mathrm{Cl}^{-}$loss observed only in the presence of $\mathrm{Na}^{+}$channel inhibition (Stys and LoPachin, 1998) suggests that a combination of $\mathrm{Na}^{+}$channel and KCC blockade may be more protective than either agent alone. Mean CAP area recovery was significantly improved after anoxia after the addition of furosemide to TTX (Figs. 7C, 9), compared with TTX alone $(91 \pm 9$ vs $74 \pm 12 \%$ TTX alone; $p<0.001 ; n=11)$.
Moreover, furosemide substantially normalized the shapes of the post-anoxic CAPs (see next section). However, this drug combination was not more effective in OGD, producing a recovery of only $50 \pm 19 \%$ (vs $56 \pm 4 \%$ in TTX alone; $n=14 ; p>0.05$ ) (see Fig. 9).

Axoplasmic $\mathrm{Ca}^{2+}$ is known to increase during anoxia (Stys and LoPachin, 1998); thus it was of interest to study potential $\mathrm{Ca}^{2+}$-sensitive anion transporters such as the $\mathrm{Ca}^{2+}$-activated $\mathrm{Cl}^{-}$channel during anoxia/ischemia. Inhibition of $\mathrm{Ca}^{2+}$ activated $\mathrm{Cl}^{-}$channels with $50 \mu \mathrm{M}$ niflumic acid (Scott et al., 1988; Currie et al., 1995), during $1 \mathrm{hr}$ normoxic perfusion, caused a minor insignificant depression of the CAP. Niflumic acid unexpectedly worsened post-anoxic CAP recovery ( $6 \pm 1$ vs $26 \pm$ $6 \%$ in ACSF alone; $p<0.001 ; n=6$ ) (Figs. $8 A, 9$ ), in contrast to KCC inhibition, which improved outcome (see above). Similarly, during in vitro ischemia, CAP recovery was also worse with niflumic acid treatment $(3 \pm 1$ vs $8 \pm 3 \%$ in ACSF alone; $p<0.01 ; n=$ 3) (Figs. 8B, 9).

\section{Compound action potential wave-shape recovery}

Combined treatment with furosemide + TTX not only improved CAP area recovery after anoxia, but also appeared to significantly improve the shape of the response, which in part reflects the preservation of normal conduction velocities of the constituent fibers. To quantify these observations we devised a measure of the shape of the CAP compared with the control wave-shape before injury, independent of CAP magnitude. This "wave-shape fidelity index" was calculated by first normalizing the areas between 

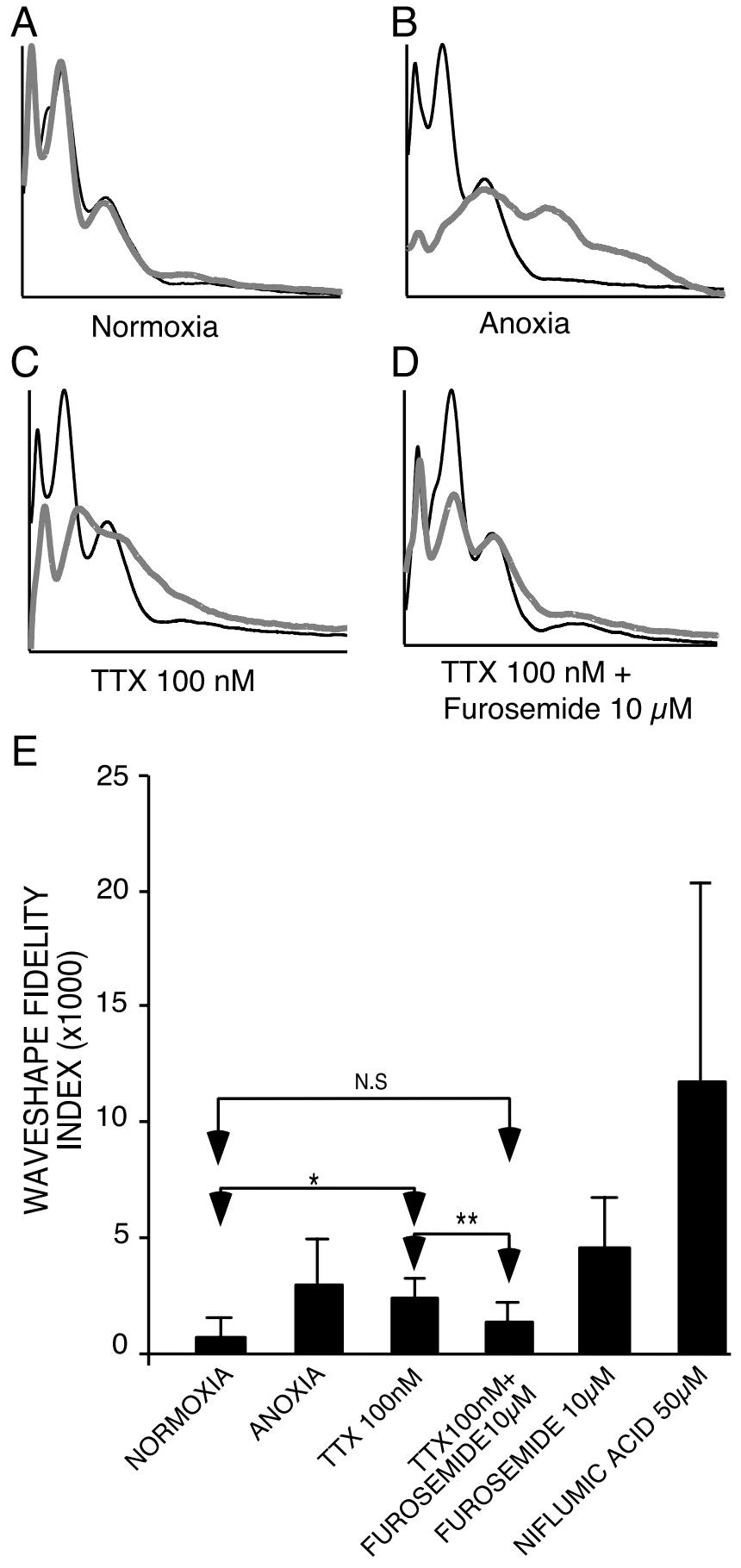

Figure 10. Panels $A-D$, Representative tracings (normalized with respect to CAP area) of normoxic, untreated anoxic, post-anoxic/washed nerves treated with TTX (100 nM) and TTX + furosemide $(10 \mu \mathrm{M})$, respectively. Black and gray curves denote control and post-anoxic recordings, respectively. As expected with normoxia, there is very little change in the wave-shape over time; however, with anoxia/reoxygenation, the wave-shape becomes very distorted. TTX results in a significant recovery of CAP area, but the wave-shapes (particularly latencies of the slower peaks) remained significantly distorted. With addition of the KCC blocker furosemide, the wave-shape is improved further, and the fidelity index is not different from time-matched normoxic controls $(p=0.20)$. The peak latencies of the pre-anoxic and post-anoxic waves are similar, indicating a return of not only the number of fibers able to conduct, but also normalization of the conduction velocities of constituent fibers. $E$, Summary of wave-shape fidelity indices. The lowest index was obtained with time-matched normoxic controls indicating little change in wave-shape with control incubation. Although TTX provided a robust recovery of CAP area, the wave-shape remained noticeably distorted (prolonged peak 2 latency, absence of peak 3), reflected by an index approaching that for anoxic nerves alone (without TTX). the control CAP before injury and response after treatment, by scaling the smaller waveform so that areas are equal. Next a pointby-point squared difference was calculated between the two CAPs, and these squared differences averaged to yield a single numerical index. In mathematical terms:

$$
F=\frac{\sum_{\mathrm{i}}^{n}\left(w_{0 \mathrm{i}}-\frac{A_{0}}{A_{1}} w_{1 \mathrm{i}}\right)^{2}}{n},
$$

where $F$ is the "wave-shape fidelity index," $w_{0}$ and $w_{1}$ are control and post-treatment CAP waveforms, respectively, $A_{0}$ and $A_{1}$ are control and post-treatment CAP areas, and $n$ is the number of points in each waveform.

An index of zero denotes a post-treatment wave-shape that is identical to control, regardless of its size. An increasing index indicates a wave-shape that differs more and more from control (again independent of magnitude). Selected normalized waveforms are shown in Figure $10 A-D$, and indices for various treatments are summarized in Fig 10E. Of the various treatments tested, combined application of TTX and furosemide was the most successful in restoring CAP shape after anoxic exposure; indeed, wave-shapes were not statistically different between this treatment group and time-matched normoxic controls, indicating that not only did this combination of drugs allow recovery of CAP area, but the configuration of the CAP was restored to near normal. This is in contrast to TTX alone, which was very effective at protecting CAP area but resulted in distorted wave-shapes reflected by a higher wave-shape fidelity index.

\section{Immunolocalization of KCC}

Figure 11 shows representative confocal microscopic images of rat optic nerve immunostained for different KCC isoforms. The red channel outlines axons stained with neurofilament, and green shows KCC stained with isoform-specific antibodies. Strong KCC3a signal was found on optic nerve astrocytes and their processes (Fig. 11A,B). Weaker KCC3a signal was found in the myelin of many larger axons (Fig. 11 $A$, inset).

There was more modest but reproducible, often punctate, KCC3 signal in the myelin sheaths of larger axons (Fig. 11C,D). KCC2 appeared more widespread, with signal in cell bodies of oligodendrocytes, and also within axon cylinders (hence the orange hue in Fig. $11 \mathrm{E}$, representing colocalization of green KCC2 fluorescence and red NF160). KCC1 staining was very weak, diffusely localized, and not consistently stronger than controls, so no conclusions about its presence or localization could be drawn (data not shown).

\section{Discussion}

In adult mammalian neurons, the $\mathrm{Cl}^{-}$gradient is influenced by a number of systems, including the KCC and NKCC cotransporters (for review, see Alvarez-Leefmans, 1990). KCC2, the neuronal isoform, appears to mainly extrude $\mathrm{Cl}^{-}$out of the cell (Payne et al., 1996). By lowering the internal $\left[\mathrm{Cl}^{-}\right]$during development, there is a switch in the GABA response from depolarizing to hyperpolarizing (Rivera et al., 1999). In immature rat optic nerve axons, a significant proportion of resting conductance depends

$\leftarrow$

In contrast, furosemide not only improved CAP area recovery but substantially improved waveshapes as well, reducing the mean index to a value not different from normoxic controls. Niflumic acid worsened CAP area recovery and wave-shape distortion. ${ }^{*} p<0.05 ;{ }^{* *} p<0.01$. 

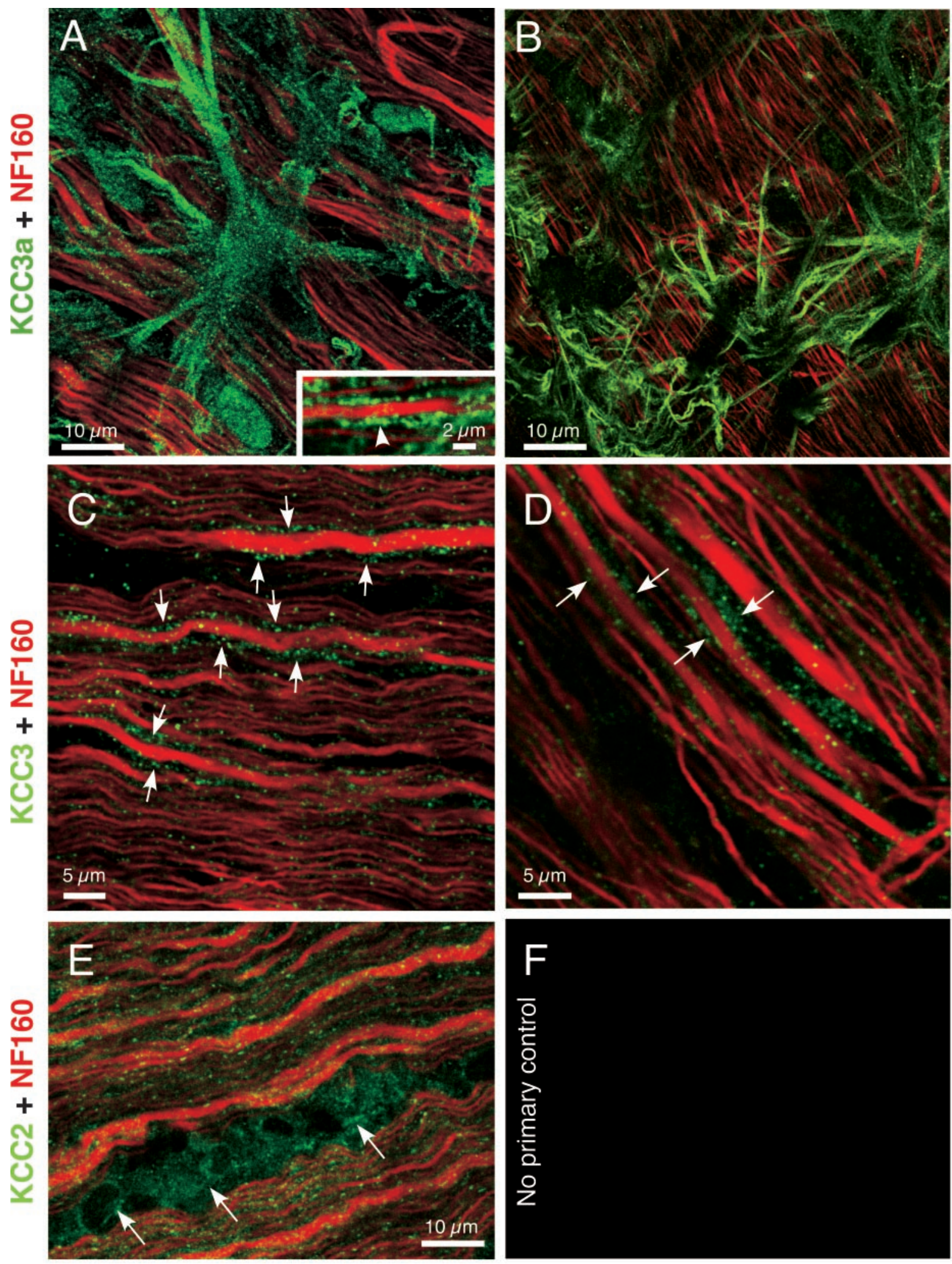

Figure 11. Laser scanning confocal micrographs showing immunohistochemical localization of different KCC isoforms (green) in rat optic nerve (axons stained with NF160 in red). A, B, There was strong KCC3a signal in astrocytes, and occasional signal in the myelin of larger axons (inset, arrowhead). C, D, Less intense but reproducible, often punctate, KCC 3 signal was observed in the myelin sheath of larger axons. Because all axons are myelinated in mature optic nerve, fluorescence immediately adjacent to axon cylinders as seen here is consistently localized to the sheath rather than glial processes. E, KCC2 was clearly present in cell bodies of oligodendrocytes (arrows) and also diffusely in the optic nerve, including signal within axon cylinders (appearing as a more orange hue because of colocalization with red NF160 signal; compare with a more pure red neurofilament signal in the other panels). $F$, Controls with $1^{\circ}$ antisera omitted were clean. 

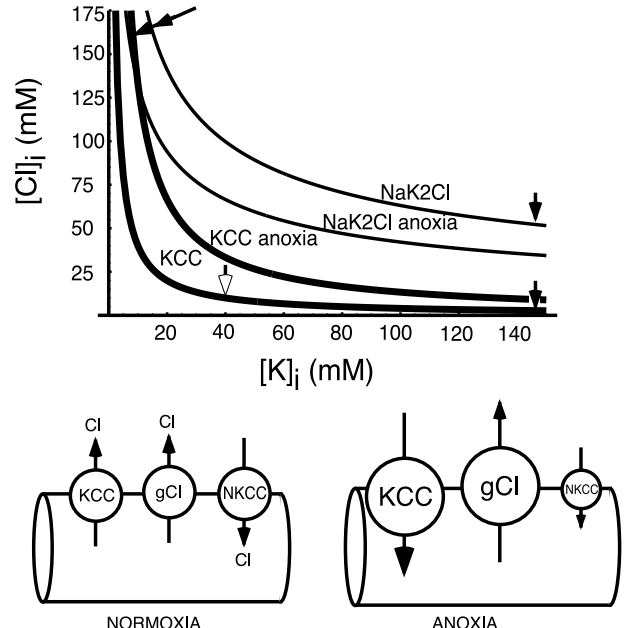

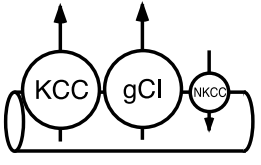

ANOXIA + TTX

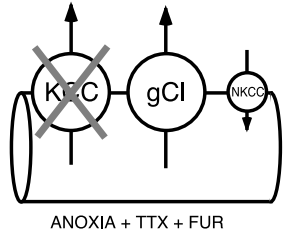

ANOXIA + TTX + FUR
Figure 12. Graph shows calculated theoretical $\mathrm{Cl}^{-}$equilibrium concentrations that would be achieved by the $\mathrm{KCC}$ and Na-K-2Cl cotransport (NKCC) as a function of axoplasmic $\left[\mathrm{K}^{+}\right]$under various conditions. In normal axons, the high transmembrane $\mathrm{K}^{+}$gradient favors a low $\left[\mathrm{Cl}^{-}\right]_{\mathrm{i}}$ maintained by $\mathrm{KCC}$ and $\sim 55 \mathrm{mMCl}^{-}$by NKCC (solid arrows). During anoxia, with collapse of the $\mathrm{K}^{+}$gradient, both $\mathrm{KCC}$ and $\mathrm{NKCC}$ will attempt to import $\mathrm{Cl}^{-}$to very high concentrations (double solid arrow). Anoxia in the presence of TTX sees residual $\mathrm{K}^{+}{ }_{\text {i }}$ concentrated back up to $\sim 55 \mathrm{~mm}$ because of water loss, thereby maintaining the $\mathrm{KCC}$ in a $\mathrm{Cl}^{-}$efflux mode (open arrow). Bottom panels illustrate hypothetical $\mathrm{Cl}^{-}$fluxes in anoxic optic nerve axons under various conditions. $i$, In normal axons, an equilibrium between $\mathrm{Cl}^{-}$efflux ( $\mathrm{KCC}$ and various $\mathrm{Cl}^{-}$ channels) and influx (NKCC) maintains $\left[\mathrm{Cl}^{-}\right]$above what would be expected from passive distribution. $i i$, The collapse of the $\mathrm{K}^{+}$gradient during anoxia will drive the $\mathrm{KCC}$ to accumulate $\mathrm{Cl}^{-}$, which is mostly compensated for by activation of $\mathrm{Cl}^{-}$channels; blocking these with niflumic acid worsens outcome (see Results). $\mathrm{Na}^{+}$and $\mathrm{K}^{+}$exchange across the axolemma in an electroneutral manner through various channels. The drop in ATP levels may reduce NKCC activity. iii, Blocking $\mathrm{Na}^{+}$influx into anoxic axons with $\mathrm{TTX}$ prevents $\mathrm{Na}^{+}$from entering; instead, electroneutrality is maintained by $\mathrm{Cl}^{-}$egress, through $\mathrm{KCC}$ [the loss of water concentrates axoplasmic $\mathrm{Na}^{+}$such that $\mathrm{KCC}$ remains biased in the $\mathrm{Cl}^{-}$-efflux direction (open arrow, graph)] and $\mathrm{Cl}^{-}$channels $\left(\mathrm{Cl}^{-}\right.$is also concentrated such that $E_{\mathrm{Cl}}$ remains much more positive than the resting membrane potential favoring $\mathrm{Cl}^{-}$loss), resulting in shrinkage and mechanical disruption. $\mathrm{iv}$, Addition of furosemide to block $\mathrm{KCC}$ reduces $\mathrm{Cl}^{-}$loss and tissue damage, possibly by helping preserve volume and mechanical integrity. Anoxic depolarization is also reduced, perhaps by decreasing $\mathrm{K}^{+}$loss because of the lower capacity for electroneutral co-efflux of $\mathrm{Cl}^{-}$ anions.

on $\mathrm{Cl}^{-}$(Connors and Ransom, 1984). Indeed, three types of $\mathrm{Cl}^{-}$ channels were found on myelinated peripheral Xenopus sciatic nerve axons by single channel recordings ( $\mathrm{Wu}$ and Shrager, 1994), although direct evidence of such channels in CNS axons is lacking. Stys et al. (1997) showed that $\mathrm{Cl}^{-}$is not passively distributed but instead has a concentration significantly above its predicted passive level of $7 \mathrm{~mm}$; resting axoplasmic $\left[\mathrm{Cl}^{-}\right]_{\mathrm{i}}$ is in the range of 40-50 $\mathrm{mm}$, indicating active accumulation into fibers, likely mediated at least in part by $\mathrm{Na}-\mathrm{K}-2 \mathrm{Cl}$ cotransport that favors a predicted resting $\left[\mathrm{Cl}^{-}\right]_{\mathrm{i}}$ of $55 \mathrm{~mm}$ (Stys et al., 1997) (Fig. 12). Using immunohistochemistry, Alvarez-Leefmans et al. (2001) confirmed the presence of $\mathrm{Na}-\mathrm{K}-2 \mathrm{Cl}$ cotransporter on the membranes of both axons and Schwann cells in peripheral nerves. Using in situ hybridization, others have demonstrated $\mathrm{Na}-\mathrm{K}-2 \mathrm{Cl}$ cotransporter mRNA in both gray and white matter areas in rat CNS, indicating that this $\mathrm{Cl}^{-}$regulator appears widely distributed in the mammalian nervous system (Kanaka et al., 2001). In central axons, $\left[\mathrm{Cl}^{-}\right]$appears to be determined by a coordinated interplay of accumulating (e.g., Na-K-2Cl cotransport) systems passive and coupled efflux, mediated in part by channels and other $\mathrm{Cl}^{-}$regulatory pathways such as the KCC.

Previous studies on white matter anoxia, ischemia, and trauma established the importance of axonal $\mathrm{Na}^{+}$influx as a major event in the injury cascade (for review, see Stys, 1998). Our results agree with others whose general finding was that blockade of TTX-sensitive $\mathrm{Na}^{+}$channels during injury was protective as assessed by electrophysiological, biochemical, and structural methods (Fern et al., 1993; Agrawal and Fehlings, 1996; Imaizumi et al., 1997; Leppanen and Stys, 1997; Teng and Wrathall, 1997; Jiang and Stys, 2000). The normal adult optic nerve CAP configuration arises from an ordered segregation of fiber conduction velocities, in turn dependent on fiber diameters and myelination in the maturing animal (Foster et al., 1982). One might expect the partially protective effects of TTX to be manifested in elements that possess substantial densities of $\mathrm{Na}^{+}$channels, i.e., axons rather than glia or the myelin sheath. Ultrastructural examination of anoxic optic nerve suggests that glial damage may be attributable more to volume disruption rather than cytoskeletal dissolution as occurs in the axon cylinder (Waxman et al., 1994). This implies that volume changes in glial elements, potentially including the myelin sheath, may play an important role in causing serious alterations in fiber conduction velocities, which would adversely affect information coding in white matter tracts or result in complete propagation failure in fibers with more severely disrupted axo-glial architecture. Our immunolocalization data suggest that the KCC may contribute to such $\mathrm{Cl}^{-}$dependent volume alterations under pathological conditions in both axons and glia and the myelin sheath (Fig. 11). Because $\mathrm{Cl}^{-}$ has been shown to participate in various regulatory volume processes (for review, see O'Neill, 1999), modulation of such pathways during injury might reduce such deleterious volume changes, helping to preserve normal conduction velocity distributions. In our study, the ability of furosemide to normalize CAP wave-shape after anoxia and ischemia is consistent with the idea that KCC mediates pathological $\mathrm{Cl}^{-}$flux; the resultant osmotic and water shifts are likely responsible for mechanical perturbation of subcellular architecture and disturbances of action potential propagation. We attempted to determine whether other $\mathrm{Cl}^{-}$ transporters contributed to this process by applying DIDS, a broad-spectrum anion transport blocker. Unfortunately this compound caused a severe and irreversible depression of CAP amplitude, possibly because of its blocking effect on voltagegated $\mathrm{Na}^{+}$channels (Liu et al., 1998), so we were unable to assess any putative protective effect on CAP recovery. However, the incremental sparing of anoxic depolarization observed with DIDS compared with furosemide (both in the presence of TTX) (Fig. 4) suggests that additional anion transporters may play a role.

Under pathophysiological conditions such as anoxia/ischemia, $\left[\mathrm{Cl}^{-}\right]_{\mathrm{i}}$ often increases in gray matter (Jiang et al., 1992; Taylor et al., 1999). Moreover, CA1 pyramidal cells subjected to hypoxia displayed a delayed hypoxic depolarization in the presence of $\mathrm{Cl}^{-}$transport inhibitors (Muller, 2000). Figure 12 summarizes theoretical calculations of equilibrium $\mathrm{Cl}^{-}$concentrations under normal and anoxic conditions on the basis of data from optic nerve (Stys et al., 1997). Under normal conditions (Fig. 12, single solid arrowheads), KCC attempts to maintain $\left[\mathrm{Cl}^{-}\right]_{\mathrm{i}}$ at low levels, well below $10 \mathrm{~mm}$, whereas $\mathrm{Na}-\mathrm{K}-2 \mathrm{Cl}$ co- 
transport will accumulate $\mathrm{Cl}^{-}$toward an equilibrium concentration of $\approx 55 \mathrm{~mm}$. Actual resting axonal $\left[\mathrm{Cl}^{-}\right]$lies between these two values, reflecting a balance between these two opposing $\mathrm{Cl}^{-}$ transport systems. During anoxia, with a significant reduction of $\left[\mathrm{K}^{+}\right]_{\mathrm{i}}$ (LoPachin and Stys, 1995; Stys and LoPachin, 1998) and a parallel rise in $\left[\mathrm{K}^{+}\right]_{\mathrm{o}}$ (Ransom et al., 1992), both transporters will be biased toward strong $\mathrm{Cl}^{-}$accumulation (Fig. 12, double arrow) and likely cause significant cellular volume deregulation. Surprisingly, in contrast to gray matter, there is little change in axonal or glial $\left[\mathrm{Cl}^{-}\right]_{\mathrm{i}}$ in anoxic white matter (LoPachin and Stys, 1995; Stys and LoPachin, 1998). One $\mathrm{Cl}^{-}$efflux mechanism that may have compensated for such expected $\mathrm{Cl}^{-}$accumulation is the opening of $\mathrm{C} \mathrm{Cl}^{-}$channel, such as $\mathrm{Cl}^{-} \mathrm{Ca}$ (for review, see Scott et al., 1995; Frings et al., 2000). Calculations (LoPachin and Stys, 1995 ) reveal that axonal $V_{\mathrm{m}}$ remains more negative than $E_{\mathrm{Cl}}$, even at the end of a $60 \mathrm{~min}$ anoxic insult (Fig. 1) (axonal $V_{\mathrm{m}} \approx-44$ $\mathrm{mV}$ vs $E_{\mathrm{Cl}} \approx-30 \mathrm{mV}$ ). Glial $V_{\mathrm{m}}$ is also estimated to be more negative than $E_{\mathrm{Cl}}$. This indicates that $\mathrm{Cl}^{-}$flux through an uncoupled transporter such as a channel would be continuously directed outward. For this reason, $\mathrm{Cl}^{-}$Ca would be well poised to serve as a compensatory system because a rise in free $\left[\mathrm{Ca}^{2+}\right]$ will almost always be a feature of a pathological state such as anoxia/ ischemia. Consistent with this hypothesis was the finding of Duchen (1990) who showed an enhancement of $\mathrm{Cl}^{-}$Ca current during anoxia in DRG neurons. This would also explain the deleterious effects of $\mathrm{Cl}^{-}$Ca channel inhibition by niflumic acid, which likely hindered the ability of the optic nerve to compensate for an abnormal influx of $\mathrm{Cl}^{-}$through coupled transporters, as assessed by CAP area recovery (Figs. 8, 9) and wave-shape (Fig. 10). Other types of $\mathrm{Cl}^{-}$channels blocked by niflumic acid such as volume-regulated channels (Leaney et al., 1997) could also participate in this mechanism.

Stys and LoPachin (1998) suggested that $\mathrm{KCl}$ cotransport may act as a parallel pathway for $\mathrm{K}^{+}$and $\mathrm{Cl}^{-}$loss during anoxia during concomitant $\mathrm{Na}^{+}$channel blockade. Under these conditions, axonal volume was noted to decrease markedly (Waxman et al., 1994) along with water content (LoPachin and Stys, 1995; Stys and LoPachin, 1998). With the major $\mathrm{Na}^{+}$influx route blocked by TTX, it is likely that ionic rundown may switch from $\mathrm{Na}^{+}-\mathrm{K}^{+}$exchange to a parallel efflux of $\mathrm{K}^{+}$and $\mathrm{Cl}^{-}$(and likely other anions); both modes will maintain electroneutrality, but in contrast, the latter will drag water out of the cytosol, causing cell shrinkage and possibly mechanical damage (Waxman et al., 1994). Because the water loss will substantially concentrate remaining intracellular ions (axoplasmic $\left[\mathrm{K}^{+}\right]$estimated at $\sim 55$ $\mathrm{mM}$ at the end of $60 \mathrm{~min}$ of anoxia in TTX-treated optic nerves vs $\sim 15 \mathrm{~mm}$ in untreated anoxic nerves), despite a loss of $90 \%$ of total axoplasmic $\mathrm{K}^{+}$under both conditions (LoPachin and Stys, 1995; Stys and LoPachin, 1998), the KCC will remain biased in the $\mathrm{Cl}^{-}$efflux mode (Fig. 12, open arrowhead) and would be positioned to remove $\mathrm{K}^{+}$and $\mathrm{Cl}^{-}$from the cytoplasm. Indeed, whereas the $\mathrm{Na}-\mathrm{K}-2 \mathrm{Cl}$ cotransporter would attempt to accumulate $\mathrm{Cl}^{-}$back into cells under such conditions, its activity will be reduced by a fall in ATP levels (Russell, 2000), whereas an ATP decrease will activate KCC (Ortiz-Carranza et al., 1996); therefore under anoxic conditions the transport rate of the $\mathrm{Na}-\mathrm{K}-2 \mathrm{Cl}$ cotransporter may be greatly diminished, unmasking the KCCand $\mathrm{Cl}^{-}$channel-mediated $\mathrm{Cl}^{-}$extrusion, precisely what is observed with direct axonal $\left[\mathrm{Cl}^{-}\right]$measurements (Stys and LoPachin, 1998). This scenario might explain why blocking KCC with furosemide was protective during anoxia: with concomitant $\mathrm{Na}^{+}$channel blockade, KCC inhibition reduced the excessive $\mathrm{Cl}^{-}$export while decreasing abnormal $\mathrm{Cl}^{-}$influx under condi- tions in which $\mathrm{Na}^{+}$channels were not blocked. Therefore, excessive $\mathrm{Cl}^{-}$movements in either direction may have deleterious effects on volume regulation resulting in mechanical injury. These findings may have implications for the design of neuroprotective strategies, whereby concomitant inhibition of $\mathrm{Na}^{+}$channels and KCC could result in better outcome than with blockade of either pathway alone.

\section{References}

Agrawal SK, Fehlings MF (1996) Mechanisms of secondary injury to spinal cord axons in vitro: role of $\mathrm{Na}^{+}, \mathrm{Na}^{+}-\mathrm{K}^{+}$-ATPase, the $\mathrm{Na}^{+}-\mathrm{H}^{+}$exchanger, and the $\mathrm{Na}^{+}-\mathrm{Ca}^{2+}$ exchanger. J Neurosci 16:545-552.

Alvarez-Leefmans FJ (1990) Intracellular $\mathrm{Cl}^{-}$regulation and synaptic inhibition in vertebrate and invertebrate neurons. In: Chloride channels and carriers in nerve, muscle and glia (Alvarez-Leefmans FJ, Russell JM, eds), pp 109-158. New York: Plenum.

Alvarez-Leefmans FJ, Leon-Olea M, Mendoza-Sotelo J, Alvarez FJ, Anton B, Garduno R (2001) Immunolocalization of the Na-K-Cl cotransporter in peripheral nervous tissue of vertebrates. Neuroscience 104:569-582.

Cabantchik ZI, Greger R (1992) Chemical probes for anion transporters of mammalian cell membranes. Am J Physiol 262:C803-827.

Clark S, Jordt SE, Jentsch TJ, Mathie A (1998) Characterization of the hyperpolarization-activated chloride current in dissociated rat sympathetic neurons. J Physiol (Lond) 506:665-678.

Connors BW, Ransom BR (1984) Chloride conductance and extracellular potassium concentration interact to modify the excitability of rat optic nerve fibers. J Physiol (Lond) 355:619-633.

Currie KP, Wootton JF, Scott RH (1995) Activation of $\mathrm{Ca}^{2+}$-dependent $\mathrm{Cl}^{-}$currents in cultured rat sensory neurons by flash photolysis of DMnitrophen. J Physiol (Lond) 482:291-307.

Duchen MR (1990) Effects of metabolic inhibition on the membrane properties of isolated mouse primary sensory neurones. J Physiol (Lond) 424:387-409.

Estevez AY, O’Regan MH, Song D, Phillis JW (1999) Effects of anion channel blockers on hyposmotically induced amino acid release from the in vivo rat cerebral cortex. Neurochem Res 24:447-452.

Fern R, Ransom BR, Stys PK, Waxman SG (1993) Pharmacological protection of CNS white matter during anoxia: actions of phenytoin, carbamazepine and diazepam. J Pharmacol Exp Ther 266:1549-1555.

Foster RE, Connors BW, Waxman SG (1982) Rat optic nerve: electrophysiological, pharmacological and anatomical studies during development. Brain Res 3:371-386.

Frings S, Reuter D, Kleene SJ (2000) Neuronal $\mathrm{Ca}^{2+}$-activated $\mathrm{Cl}^{-}$ channels-homing in on an elusive channel species. Prog Neurobiol 60:247-289.

Gillen CM, Brill S, Payne JA, Forbush B (1996) Molecular cloning and functional expression of the $\mathrm{K}-\mathrm{Cl}$ cotransporter from rabbit, rat, and human: a new member of the cation-chloride cotransporter family. J Biol Chem 271:16237-16244.

Imaizumi T, Kocsis JD, Waxman SG (1997) Anoxic injury in the rat spinal cord: pharmacological evidence for multiple steps in $\mathrm{Ca}^{2+}$-dependent injury of the dorsal columns. J Neurotrauma 14:299-311.

Jarolimek W, Lewen A, Misgeld U (1999) A furosemide-sensitive $\mathrm{K}^{+}-\mathrm{Cl}^{-}$ cotransporter counteracts intracellular $\mathrm{Cl}^{-}$accumulation and depletion in cultured rat midbrain neurons. J Neurosci 19:4695-4704.

Jiang C, Agulian S, Haddad GG (1992) $\mathrm{Cl}^{-}$and $\mathrm{Na}^{+}$homeostasis during anoxia in rat hypoglossal neurons: intracellular and extracellular in vitro studies. J Physiol (Lond) 448:697-708.

Jiang Q, Stys PK (2000) Calpain inhibitors confer biochemical, but not electrophysiological, protection against anoxia in rat optic nerves. J Neurochem 74:2101-2107.

Kaila K (1994) Ionic basis of $\mathrm{GABA}_{\mathrm{A}}$ receptor channel function in nervous system. Prog Neurobiol 42:489-537.

Kanaka C, Ohno K, Okabe A, Kuriyama K, Itoh T, Fukuda A, Sato K (2001) The differential expression patterns of messenger RNAs encoding $\mathrm{K}-\mathrm{Cl}$ cotransporter $(\mathrm{KCC} 1,2)$ and $\mathrm{Na}-\mathrm{K}-2 \mathrm{Cl}$ cotransporter $(\mathrm{NKCC} 1)$ in the rat nervous system. Neuroscience 104:933-946.

Kauppinen RA, Nicholls DG (1986) Failure to maintain glycolysis in anoxic nerve terminals. J Neurochem 47:1864-1869.

Leaney JL, Marsh SJ, Brown DA (1997) A swelling-activated chloride current in rat sympathetic neurones. J Physiol (Lond) 501:555-564. 
Leppanen L, Stys PK (1997) Ion transport and membrane potential in CNS myelinated axons. II. Effects of metabolic inhibition. J Neurophysiol 78:2095-2107.

Liu J, Lai ZF, Wang XD, Tokutomi N, Nishi K (1998) Inhibition of sodium current by chloride channel blocker 4, 4' -diisothiocyanatostilbene-2, 2' disulfonic acid (DIDS) in guinea pig cardiac ventricular cells. J Cardiovasc Pharmacol 31:558-567.

LoPachin Jr RM, Stys PK (1995) Elemental composition and water content of rat optic nerve myelinated axons and glial cells: effects of in vitro anoxia and reoxygenation. J Neurosci 15:6735-6746.

Mount DB, Mercado A, Song L, Xu J, George Jr AL, Delpire E, Gamba G (1999) Cloning and characterization of KCC3 and KCC4, new members of the cation-chloride cotransporter gene family. J Biol Chem 274: $16355-16362$.

Muller M (2000) Effects of chloride transport inhibition and chloride substitution on neuron function and on hypoxic spreading-depression-like depolarization in rat hippocampal slices. Neuroscience 97:33-45.

O’Neill WC (1999) Physiological significance of volume-regulatory transporters Am J Physiol 276:C995-C1011.

Ortiz-Carranza O, Adragna NC, Lauf PK (1996) Modulation of K-Cl cotransport in volume-clamped low-K sheep erythrocytes by $\mathrm{pH}$, magnesium and ATP. Am J Physiol 271:C1049-1058.

Payne JA (1997) Functional characterization of the neuronal-specific K-Cl cotransporter: implications for $\left[\mathrm{K}^{+}\right]_{\mathrm{o}}$ regulation. Am J Physiol 273: C1516-C1525.

Payne JA, Stevensen TJ, Donaldson LF (1996) Molecular characterization of a putative $\mathrm{K}-\mathrm{Cl}$ cotransporter in rat brain. A neuronal-specific isoform. J Biol Chem 271:16245-16252.

Pearson MM, Lu J, Mount DB, Delpire E (2000) Expression of KCl cotransporter (KCC3) in the central nervous system: concurrence with myelination. FASEB J 14:A351.

Pearson MM, Lu J, Mount DB, Delpire E (2001) Localization of the KCl cotransporter KCC3 in the central and peripheral nervous systems: expression in the choroids plexus, large neurons and white matter tracts. Neuroscience 103:481-491.

Ransom BR, Walz W, Davis PK, Carlini WG (1992) Anoxia-induced changes in extracellular $\mathrm{K}^{+}$and $\mathrm{pH}$ in mammalian central white matter. J Cereb Blood Flow Metab 12:593-602.

Rivera C, Voipio J, Payne JA, Ruusuvuori E, Lahtinen H, Lamsa K, Pirvola U, Saarma M, Kaila K (1999) The K-Cl co-transporter KCC2 renders GABA hyperpolarizing during neuronal maturation. Nature 397: 251-255.

Russell JM (2000) Sodium-potassium-chloride cotransport. Physiol Rev 80:211-276.

Sabri MI, Ochs S (1971) Inhibition of glyceraldehyde-3-phosphate dehy- drogenase in mammalian nerve iodoacetic acid. J Neurochem 18:1509-1514.

Sakai S, Tosaka T (1999) Analysis of hyposmolarity-induced taurine efflux pathways in the bullfrog sympathetic ganglia. Neurochem Int 34:203-212.

Scott RH, Mcguirk SM, Dolphin AC (1988) Modulation of divalent cationactivated chloride ion currents. Br J Pharmacol 94:653-662.

Scott RH, Sutton KG, Griffin A, Stapleton SR, Currie KP (1995) Aspects of calcium-activated chloride currents: a neuronal perspective. Pharmacol Ther 66:535-565.

Stämpfli R (1954) A new method for measuring membrane potentials with external electrodes. Experientia 10:508-509.

Stys PK (1998) Anoxic and ischemic injury of myelinated axons in CNS white matter: from mechanistic concepts to therapeutics. J Cereb Blood Flow Metab 18:2-25.

Stys PK, LoPachin RM (1998) Mechanisms of calcium and sodium fluxes in anoxic myelinated central nervous system axons. Neuroscience 82:21-32.

Stys PK, Ransom BR, Waxman SG (1991) Compound action potential of nerve recorded by suction electrode: a theoretical and experimental analysis. Brain Res 546:18-32.

Stys PK, Waxman SG, Ransom BR (1992) Ionic mechanisms of anoxic injury in mammalian CNS white matter: role of $\mathrm{Na}^{+}$-channels and $\mathrm{Na}^{+}$. $\mathrm{Ca}^{2+}$ exchanger. J Neurosci 12:430-439.

Stys PK, Sontheimer H, Ransom BR, Waxman SG (1993) Noninactivating, tetrodotoxin-sensitive $\mathrm{Na}^{+}$conductance in rat optic nerve axons. Proc Natl Acad Sci USA 90:6976-6980.

Stys PK, Lehning E, Saubermann AJ, LoPachin Jr RM (1997) Intracellular concentrations of major ions in rat myelinated axons and glia: calculations on the basis of electron probe $\mathrm{x}$-ray microanalyses. J Neurochem 68:1920-1928.

Tadic V (1992) The in vivo effects of cyanide and its antidotes on rat brain cytochrome oxidase activity. Toxicology 76:59-67.

Taylor CP, Weber ML, Gaughan CL, Lehning EJ, LoPachin RM (1999) Oxygen/glucose deprivation in hippocampal slices: altered intraneuronal elemental composition predicts structural and functional damage. J Neurosci 19:619-629.

Teng YD, Wrathall JR (1997) Local blockade of sodium channels by tetrodotoxin ameliorates tissue loss and long-term functional deficits resulting from experimental spinal cord injury. J Neurosci 17:4359-4366.

Waxman SG, Black JA, Ransom BR, Stys PK (1994) Anoxic injury of rat optic nerve: ultrastructural evidence for coupling between $\mathrm{Na}^{+}$influx and $\mathrm{Ca}^{2+}$-mediated injury in myelinated CNS axons. Brain Res 644:197-204.

Wu JV, Shrager P (1994) Resolving three types of chloride channels in demyelinated Xenopus axons. J Neurosci Res 38:613-620. 